\title{
Intelligent Manufacturing System for Next Generation Factories
}

\author{
M. Rajora ${ }^{1, b}$, P. Zou ${ }^{2}$, and S. Y. Liang ${ }^{1,2, a^{*}}$ \\ ${ }^{1}$ George W. Woodruff School of Mechanical Engineering, Georgia Institute of Technology, \\ Atlanta, Georgia 30332-0405, USA \\ asteven.liang@me.gatech.edu \\ bmrajora3@gatech.edu \\ www.gatech.edu \\ ${ }^{2}$ Mechanical Engineering College, Donghua University, \\ Songjiang District, Shanghai 201620, China \\ pan.zou@me.gatech.edu \\ www.dhu.edu.cn
}

Keywords: Intelligent Systems; Intelligent Design, Scheduling, Maintenance, and Control, Energy Conservation;

\begin{abstract}
Manufacturing factories are always in pursuit of achieving higher productivity in order to satisfy the growing demands of the consumers but are often meet with challenges in achieving these goals due to various complexities. These complexities arise from the limitations of human operator's i.e. their inability to handle uncertainties, complexity, and understand/memorize large data. Intelligent manufacturing systems are positioned to yield superior results than traditional manufacturing as they are capable of analyzing, self-learning, apprehending complexity, and self-driven for quality and cost. Unlike traditional manufacturing, intelligent manufacturing systems are also able to store and analyze large amounts of production data in order to achieve higher production rate and shorten the time-tomarket. This keynote is to provide a longitudinal perspective on various aspects of recent achievements in intelligent design, scheduling, maintenance, and control. For each aspect, concept, requirement, and application implemented, methodologies deployed are also presented along with their limitations and future research directions. This keynote also presents fundamental concepts and futuristic views that the authors are currently implementing in an intelligent manufacturing system for factories next-generations.
\end{abstract}

\section{Introduction}

With the rapid development of global industry, traditional manufacturing industries are facing many challenges, such as the higher complexity and flexibility of problem, the increasing human labor cost and the urgent requirement of sustainable production. These problems create bottleneck to the traditional manufacturing system due to the operator's limitations on handling uncertainties, complexity and memorizing large amount of data.

These problems can be negated by the use of intelligent manufacturing systems that have the ability of learning, understanding complexity, engaging in various forms of reasoning, and analyzing quality and cost. The IMS(Intelligent Manufacturing System) initiative was developed to encourage global cooperation in the development of manufacturing systems to allow manufacturing firms and nations to move ahead rapidly in a global environment while maintaining their competitive edge. The emerging intelligent concepts and techniques have brought more potentials to the targets of industry. What's more, many researchers and engineers found them were widely useful and self-adaptive tools with their awareness of the realities of a given application. The manufacturing process is a complex one and can be decomposed into several components in order to deal with the challenges mentioned above. The main components that have been research in past few decades include: intelligent scheduling, design, control and maintenance system. The following paper will present each of these areas as what methodologies and algorithms are used to deal with such challenges. 


\section{Intelligent Design}

The conceptual design of any product or system aims to generate several prototypes that can meet a set of requirements. Traditionally, this task is carried out by skilled designers through an experiencebased trial-and-error procedure. The recent advancement in the area of computing has helped researches to apply intelligent techniques for designing processes. Among the intelligent techniques, Knowledge-based Systems (KBS) and Neural Networks (NN) are commonly used due to their ability to do decision making.

Typically Naraje and Kumar [ $\left.{ }^{[}\right]$developed a knowledge based system (KBS) for the automated design of deep drawing die for axisymmetric part. Their proposed system automates all the activities involved in the designing of deep drawing die such as assessment of the deep drawn parts, process planning, selection of components etc. Silva et al. ii also utilized KBS for design natural gas cogeneration plants. The knowledge in their system was represented using a combination of objectoriented modeling, rules and semantic networks.

\section{Intelligent Production Scheduling}

Scheduling, defined as the allocation of resources to tasks in order to obtain minimum makespan [iii], is a difficult task in real-life manufacturing due to complex part routing, man and machine interactions, and high product mix [iv]. Traditional scheduling depends on human operators' ability to make decisions. Traditional scheduling takes significantly longer time on large scale problems and are constrained by the experience of the human operators. Intelligent scheduling system, on the other hand, are capable of learning from historical production data, understanding the complexity of the scheduling and analyzing the outcome of the schedule.

Johnson's algorithm, as developed in 1954, is the earliest known to find the optimal solution of n-job two-machine flow shop scheduling problem. The concept behind the logic was that by minimization of the makespan would lead to a minimization of the idle time of the second machine. Since then many researchers have looked into developing algorithms for solving flow-shop and jobshop problems. Tanaka and Yoshida [v] applied Reinforcement Learning (RL) to minimize the maximum completion time, for two and three machines. In their model, the reward function was defined as the opposite number of maximum completion time. Their studies showed that an agent could learn and obtain improved schedules even if the formulation is not perfect. Haq et al. [iii] developed a hybrid neural network-genetic algorithm in order to find a sequence of jobs for a flowshop to minimize the makespan. They utilized artificial neural networks to generate an initial population for the genetic algorithm using the random insertion perturbation scheme (RIPS). Azadeh et al. $\left.{ }^{[\mathrm{vi}}\right]$ also extended their study to job-shop problems. They integrated Discrete-eventsimulation, a computer simulation algorithm, with artificial neural networks to solve the job-shop problem. In their study, processing times were considered as random variables and jobs were selected according to 10 different priority rules. These characteristics made the problem complex, stochastic, and non-linear, mimicking real-life scenarios.

\section{Intelligent Process Control}

In traditional industrial control systems, like PID controller, manipulated variables are changed manually to adjust the process and minimize the error depending on user's experience. The corresponding problems include time-delay problem, highly dependence on human's decision making and uncertainty of the quality of control schemes. While in the design of intelligent feedback controller, it is desirable to incorporate the expert knowledge of engineers so that the controller can make decisions on the choice of control algorithm and provide diagnostics on the effectiveness of the control system. It should also be able to tell if the traditional control method, such as PID control, is appropriate and if not, suggest alternative control schemes. To achieve those targets, researchers have tried different intelligent techniques based in a specific control problem.

Yao et al. [vii] proposed two control schemes in order to control the forces in a vertical machining operation on a CNC system. Scheme A consisted of a linear proportional-derivative (PD) controller and a non-linear fuzzy logic compensator (FLC) and Scheme B consisting of a linear PD and radical basic function neural network (RBFNN). Their proposed intelligent controllers were able to keep the cutting forces at a reference level when the depth of cut was increased by decreasing the feed rate. 
Mendez et al. [viii] devised a fuzzy logic system in monitor and control the finishing thread speed and strip surface temperature at the exit of finishing mill stands. Their experimental results showed that their FLC was better than a math-model used to predict the same results. Zuperl et al.[ix] designed an adaptive control system in order to control the forces in an end milling process. In their proposed method the cutting conditions were first optimized off-line using an adaptive neuro-fuzzy inference system (ANFIS) and a Particle Swarm Optimization (PSO) algorithm and sent to the CNC controller of the milling machine. During the cutting operation the forces were measured online and send to the neural control scheme which adjusted the federate in order to maintain maximum material removal rate and main the cutting forces as close to the reference value. The experimental results showed that their proposed model had a $24 \%$ higher efficiency than traditional CNC milling system as shown in table 2 .

\section{Intelligent Maintenance}

In manufacturing, machines suffer increasing wear with usage and age, which leads to low reliability and high operational cost $[\mathrm{x}]$. A failure in these machines results in not only the loss of productivity but also timely services to customers [xi]. These failures can also cause catastrophic damage, personal and environmental if they remained unchecked for an extended period of time. Maintenance strategies can be classified into two categories, corrective maintenance (CM) and preventive maintenance $(\mathrm{PM})$. In $\mathrm{CM}$, the maintenance is performed after the breakdown of equipment. PM can further be classified into scheduled maintenance and condition-based maintenance (CBM). In scheduled maintenance, maintenance is carried out at certain times where parts are lubricated, calibrated, and replaced. In CBM, the machines are continuously monitored in real time in order to detect faults.

Modeling of maintenance operations has aroused interest from researchers since 1960's to cut down expenses related to maintenance. Yuniarto and Labib [xii] proposed a method for PM that utilized fuzzy logic rule-based controller. Their work was based on controlling a failure-prone manufacturing system while proposing which PM method was applicable to a specific failure-prone manufacturing system. They utilized mean time to repair and mean time between failures of the system as the integrating agents. Fouad et al [xiii] also utilized a fuzzy logic based system for PM in an enterprise resource planning system. Their fuzzy system considered 44 rules and five inputs; the severity of failure, criticality of operation, equipment availability, craft utilization and availability of spare parts to provide the priority of maintenance. Samhouri $\left[{ }^{\mathrm{xiv}}\right]$ adopted genetic algorithm in order to identify whether opportunistic maintenance was favorable or not. Opportunity maintenance can be defined as a method of collecting, investigating, preplanning, and publishing a set of proposed maintenance tasks and acting on them when there is an opportunity to repair. Their approach optimized the total cost of maintenance and gave an indication about the economic of repairing or replacing a part under the strategy considered. Wu, Tian and Chen $\left[{ }^{\mathrm{xv}}\right]$ developed a CBM optimization approach based on ANN remaining life prediction information. They also developed numerical method to evaluate the cost of the CBM policy which had advantage over simulation methods used generally. Their proposed CBM approach outperformed benchmark policies in terms of cost as seen in table 1 .

Table 1: Comparison between the benchmark algorithms and the proposed CBM algorithm

\begin{tabular}{ccc}
\hline Maintenance Policy & $\begin{array}{c}\text { Expected total } \\
\text { replacement cost per } \\
\text { unit time }(\$ / \text { day })\end{array}$ & $\begin{array}{c}\text { Optimal replacement } \\
\text { time }\end{array}$ \\
\hline $\begin{array}{c}\text { Constant interval } \\
\text { replacement policy } \\
\text { Age-based }\end{array}$ & 65.18 & 58.00 \\
$\begin{array}{c}\text { replacement policy } \\
\text { Proposed CBM } \\
\text { approach }\end{array}$ & 63.07 & 59.87 \\
& 35.09 & \\
\end{tabular}




\section{Intelligent Applications on Energy}

The rapid expansion of residential and commercial regions contributes to a substantial increase in energy consumption, especially by the manufacturing industries. The study of the energy consumption management with the aim of minimizing the energy cost has become a world-wide topic of great importance, because of its significant effect on increasing energy sustainability and decreasing the manufacturing cost. However, researchers in energy engineering field have faced huge challenges due to the complexity of the energy system. In the past few years, what can be noticed is, with the emerging and rapid developing artificial intelligent technologies, more efforts have been made to solve the problem of energy management by using intelligent techniques and the results are quite inspiring. Furthermore, the successful applications of intelligent energy management system has brought more potential space and possibilities for scholars in mechanical engineering field to reduce the manufacturing cost.

\subsection{Energy Consumption Management}

The ability to predict the energy consumption ahead of time is an important aspect as it will help indicate above-normal energy usage $\left[{ }^{\mathrm{xvi}}\right]$. Due to the complexity of the problem, predicting energy consumption precisely is a difficult task. Recently, a large number of methods, elaborate or simplified, have been proposed and applied to numerous problems such as forecasting heating load, cooling demand, and electricity use in a building. The ability to predict the energy consumption using intelligent techniques has also given researchers the opportunity to investigate the minimization of energy consumption through the use of optimization techniques. The most commonly used artificial intelligence methods are Artificial Neural Network (ANN) and Support Vector Machine (SVM). Since ANN and SVM have the ability to solve non-linear problems, they are commonly used for predicting energy consumption in buildings.

Chou and Bui [ ${ }^{\text {xvii }}$ ] used a combination of support vector regression (SVR) and ANNs for modeling the healing and cooling loads in twelve simulated buildings with each having different surface area and dimensions. The root mean square error (RMSE) obtained using the ensemble approach of SVR and ANN was much better than (58.8\% in the best case scenario) the other algorithms such as classification and Regression tree (CART), Chi-squared automatic interaction detector (CHAID), and General linear regression (GLR). A comparison of the results obtained using the different methods are shown in table 2. Awan et al. [ ${ }^{\text {xviii }}$ ] used ANNs trained using artificial bee colony optimization algorithm $(\mathrm{ABC})$ in order to predict the short-term electric load forecasting for the state of Ontario. When compared to ANNs trained using Genetic Algorithm (GA) or Particle Swarm Optimization algorithm (PSO), their ANN had a testing mean absolute percentage error (MAPE) of 1.87 while ANNs trained using GA and PSO had MAPE of 5.08 and 4.44 respectively.

Nassif $\left[{ }^{\mathrm{xix}}\right]$ trained several ANNs using real time data to predict the fan power, cooling load, and the compressor power based on the parameters of the Heating Ventilation and Air Conditioning (HVAC) system. He then utilized this trained ANNs in conjunction with a GA based optimization algorithm to minimize the energy cost of the HVAC system i.e. the fan power, cooling load, and the compressor power. Using the optimization algorithm, they were able to reduce the energy cost by $11 \%$ over a period of three months. Xu et al. $\left[{ }^{\mathrm{xx}}\right]$ utilized PSO to optimize the zone temperature set-points in order to reduce the total energy consumption and the energy cost. By using predicted weather data, they were able to determine the best time and time period for pre-cooling. Using their proposed strategy they were able to save $21.37 \%$ in total cost (energy and demand).

Table 2. Heating and Cooling load predictions for using different techniques [16]

\begin{tabular}{|c|c|c|c|c|c|c|c|c|c|c|}
\hline \multirow[t]{2}{*}{ Model } & \multicolumn{5}{|l|}{ Cooling load } & \multicolumn{5}{|l|}{ Heating load } \\
\hline & RMSE $(\mathrm{kW})$ & $\operatorname{MAE}(\mathrm{kW})$ & MAPE (\%) & $R$ & SI & RMSE (kW) & $\operatorname{MAE}(\mathrm{kW})$ & MAPE (\%) & $R$ & SI \\
\hline ANN & 1.678 & 1.158 & 4.403 & 0.984 & $0.53(2)$ & 0.610 & 0.432 & 2.362 & 0.998 & $0.34(2)$ \\
\hline SVR & 1.647 & 0.890 & 2.985 & 0.985 & $0.14(1)$ & 0.346 & 0.236 & 1.132 & 0.999 & $0.00(1)$ \\
\hline CART & 1.841 & 1.157 & 4.020 & 0.981 & $0.76(3)$ & 0.800 & 0.437 & 2.104 & 0.996 & $0.51(3)$ \\
\hline CHAID & 1.859 & 1.174 & 4.104 & 0.981 & $0.82(5)$ & 0.909 & 0.469 & 2.407 & 0.995 & $0.64(4)$ \\
\hline GLR & 1.740 & 1.292 & 4.966 & 0.983 & $0.79(4)$ & 1.039 & 0.787 & 4.591 & 0.995 & $1.00(5)$ \\
\hline Combined 5 single models & 1.614 & 1.030 & 3.539 & 0.986 & 0.23 & 0.539 & 0.345 & 1.610 & 0.998 & 0.20 \\
\hline Combined 4 best single models & 1.624 & 1.021 & 3.525 & 0.985 & 0.24 & 0.526 & 0.329 & 1.593 & 0.999 & 0.19 \\
\hline Combined 3 best single models & 1.610 & 1.000 & 3.474 & 0.986 & 0.20 & 0.488 & 0.315 & 1.581 & 0.999 & 0.15 \\
\hline Combined 2 best single models & 1.566 & 0.973 & 3.455 & 0.986 & 0.11 & 0.428 & 0.300 & 1.557 & 0.999 & 0.11 \\
\hline
\end{tabular}


The energy consumption management is not only limited to energy engineering field but has also been applied to other fields. The following section will introduce the application of energy consumption management in manufacturing scheduling in order to create a more energy efficient scheduling process.

\subsection{Energy Aware Scheduling in Smart Grid Environment}

Smart Grid is another successful application of intelligent technology in energy engineering field. In the Smart Grid environment, efficient energy use will be a very important issue for economic production, since the Smart Grid introduces fluctuating real-time electricity pricing. Demand-side management for efficient energy use, which can help reduce peak load and adapt elastic demand to fluctuating electricity price and generation, will be a key component of future Smart Grid [xxi].

Traditionally, manufacturing scheduling has been focused on reducing production time and increasing throughput. Recently, however, efforts have begun to be initiated relative to developing energy-conscious scheduling strategies. Although two scheduling solutions can have the same makespan, they may have different electricity costs. Electricity rates for manufacturing industries in many countries depend on the time of the day. Such differential rates are referred to as time-of-use (TOU) rates and critical peak pricing (CPP) rates. Thus, even if the makespan of one scheduling solution is slightly longer than that of other solutions, avoiding operations at peak-load time, or on a machine that consumes more power, can reduce total production costs.

Recently there have been numerous works on intelligent scheduling optimization approach which aims to reduce manufacturing energy consumption by reducing the idling times of machines by putting them into energy saving modes or shut them down entirely [xxii,xxiii]. Mouzon et al. developed dispatching rules which could realize a significant amount of energy savings while maintaining or even reducing the total production completion time [xxiv] . Moon et al. [xxv] dealt with the unrelated parallel machine problem, by considering timedependent and machine-dependent hourly electricity costs. The problem was solved using a hybrid inserted genetic algorithm (HIGA). Gao et al. solved the multi-objective FJSP using a new approach, hybridizing a genetic algorithm with a variable neighborhood descent algorithm [ xxvi].By hybridizing particle swarm optimization as a global search, and simulated annealing as a local search, Xia and Wu also developed a hybrid approach for the multi-objective FJSP[xxvii]. Moradi et al. attempted to simultaneously minimize two objectives of the makespan for the production part, and the system unavailability for the maintenance part, by using a hybrid genetic algorithm [xxviii].

Table 3 shows that the energy-aware scheduling models can reduce the total cost by $13.3 \% \sim 36.9 \%$ in a $10 \times 10$ FJSP case. The result proves that the financial benefit of energy-aware scheduling models being applied in actual industrial production can be very inspiring.

Table 3. Comparison of total costs for the $10 \times 10$ FJSP case [27]

\begin{tabular}{|c|c|c|c|c|c|c|}
\hline \multirow{2}{*}{ Item } & \multicolumn{3}{|c|}{ TOU rates } & \multicolumn{3}{|c|}{ CPP rates } \\
\hline & Classic FJSP & Model I & Model II & Classic FJSP & Model I & Model II \\
\hline Makespan & 7 & 8 & 8 & 7 & 8 & 8 \\
\hline $\mathrm{PC}$ & 350,000 & $400,000(14.3 \%)$ & $400,000(14.3 \%)$ & 350,000 & $400,000(14.3 \%)$ & $400,000(14.3 \%)$ \\
\hline $\mathrm{EC}(+\mathrm{DGC})$ & 458,785 & $301,413(-34.3 \%)$ & $290,327(-36.7 \%)$ & 777,133 & $424,740(-45.4 \%)$ & $311,839(-59.9 \%)$ \\
\hline Total Cost & 808,785 & $701,413(-13.3 \%)$ & $690,327(-14.7 \%)$ & $1,127,133$ & $824,740(-26.8 \%)$ & $711,839(-36.9 \%)$ \\
\hline
\end{tabular}

\section{Summaries and Future Outlook}

This paper presents the application of intelligent techniques for the use of next generation factories that covers different stages of product production. The applications of the intelligent techniques have shown better performance than traditional techniques by virtue of the capability to organize, learn, predict, and optimization systematically and automatically. In addition, with the development of intelligent methodology and the increasing number of successful applications of these methodologies for the factories of the future, the intelligent industry is recently emerging as an important new trend in a wide range of industrial systems. Therefore, intelligent system has demonstrated its promise in a broad area that continues to attract multi-disciplinary talents for its development. Some of its further research directions include: life-cycle modeling of intelligent 
factories; methodology to generate the optimal option for given industrial tasks; and interaction between users and the intelligent systems in factory settings.

\section{References}

[1]. Naranje, V., \& Kumar, S. (2014). "A knowledge based system for automated design of deep drawing die for axisymmetric parts". Expert Systems with Applications, 41(4), 1419-1431.

[2]. Da Silva, J. C., Matelli, J. A., \& Bazzo, E. (2014). "Development of a knowledge-based system for cogeneration plant design: Verification, validation and lessons learned". Knowledge-Based Systems, 67, 230-243.

[3]. Noorul Haq, A., Ramanan, T. R., Shashikant, K. S., \& Sridharan, R. (2010). "A hybrid neural networkgenetic algorithm approach for permutation flow shop scheduling". International Journal of Production Research, 48(14), 4217-4231.

[4]. Mejía, G., Montoya, C., Cardona, J., \& Castro, A. L. (2012). "Petri nets and genetic algorithms for complex manufacturing systems scheduling”. International Journal of Production Research, 50(3), 791-803.

[5]. Tanaka, Y., \& Yoshida, T. (1999). "An application of reinforcement learning to manufacturing scheduling problems. Paper presented at the Systems, Man, and Cybernetics", 1999. IEEE SMC'99 Conference Proceedings. 1999 IEEE International Conference on.

[6]. Azadeh, A., Negahban, A., \& Moghaddam, M. (2012). "A hybrid computer simulation-artificial neural network algorithm for optimisation of dispatching rule selection in stochastic job shop scheduling problems". International Journal of Production Research, 50(2), 551-566.

[7]. Yao, X., Zhang, Y., Li, B., Zhang, Z., \& Shen, X. (2013). "Machining force control with intelligent compensation". The International Journal of Advanced Manufacturing Technology, 69(5-8), 1701-1715.

[8]. Méndez, G., Colás, R., Leduc, L., Lopez-Juarez, I., \& Longoria, R. (2012). "Finishing mill thread speed setup and control by interval type 1 non-singleton type 2 fuzzy logic systems". Ironmaking \& Steelmaking, 39(5), 342-354.

[9]. Zuperl, U., Cus, F., \& Reibenschuh, M. (2012).” Modeling and adaptive force control of milling by using artificial techniques". Journal of Intelligent Manufacturing, 23(5), 1805-1815.

[10].Liao, W., Wang, Y., \& Pan, E. (2012). "Single-machine-based predictive maintenance model considering intelligent machinery prognostics". The International Journal of Advanced Manufacturing Technology, 63(14), 51-63.

[11]. Yang, B.-S. (2012).” An intelligent condition-based maintenance platform for rotating machinery”. Expert Systems with Applications, 39(3), 2977-2988.

[12]. Yuniarto, M., \& Labib, A. (2006). "Fuzzy adaptive preventive maintenance in a manufacturing control system: a step towards self-maintenance". International Journal of Production Research, 44(1), 159-180.

[13].Fouad, R. H., Samhouri, M. S., \& Qamar, A. M. (2012). "An Intelligent Preventive Maintenance Scheduling in ERP Systems: A Fuzzy Logic Approach". International Journal of Advancements in Computing Technology, 4(23).

[14]. Samhouri, M. S. (2009). "An intelligent opportunistic maintenance (OM) system: a genetic algorithm approach". Paper presented at the Science and Technology for Humanity (TIC-STH), 2009 IEEE Toronto International Conference.

[15].Wu, B., Tian, Z., \& Chen, M. (2013). "Condition - based Maintenance Optimization Using Neural Network - based Health Condition Prediction”. Quality and Reliability Engineering International, 29(8), 1151-1163.

[16]. Jovanović, R. Ž., Sretenović, A. A., \& Živković, B. D. (2015).” Ensemble of various neural networks for prediction of heating energy consumption”. Energy and Buildings, 94, 189-199.

[17].Chou, J.-S., \& Bui, D.-K. (2014). "Modeling heating and cooling loads by artificial intelligence for energyefficient building design”. Energy and Buildings, 82, 437-446. 
[18]. Awan, S. M., Aslam, M., Khan, Z. A., \& Saeed, H. (2014). "An efficient model based on artificial bee colony optimization algorithm with Neural Networks for electric load forecasting”. Neural Computing and Applications, 25(7-8), 1967-1978.

[19]. Nassif, N. (2012). "Modeling and Optimization of HVAC Systems Using Artificial Intelligence Approaches". ASHRAE Transactions, 118(2).

[20].Xu, Y., Ji, K., Lu, Y., Yu, Y., \& Liu, W. (2013). "Optimal building energy management using intelligent optimization". Paper presented at the Automation Science and Engineering (CASE), 2013 IEEE International Conference on.

[21].Li, N., Chen, L., \& Low, S. H. (2011). "Optimal demand response based on utility maximization in power networks". Paper presented at the Power and Energy Society General Meeting, 2011 IEEE.

[22].Eberspächera, P., \& Verla, A. (2013). "Realizing energy reduction of machine tools through a controlintegrated consumption graph-based optimization method". Procedia CIRP, 7, 640-645.

[23]. Orio, G. D., Cândido, G., Barata, J., Bittencourt, J. L., \& Bonefeld, R. (2013). "Energy Efficiency in Machine Tools-A Self-Learning Approach". Paper presented at the Systems, Man, and Cybernetics (SMC), 2013 IEEE International Conference on.

[24].Mouzon, G., Yildirim, M. B., \& Twomey, J. (2007). "Operational methods for minimization of energy consumption of manufacturing equipment”. International Journal of Production Research, 45(18-19), 42474271.

[25].Moon, J. Y., \& Park, J. (2011). "Modeling and optimization of unrelated parallel machine scheduling problem with time-dependent and machine-dependent electricity cost". International Journal of Advanced Manufacturing Technology, 68(1-4), 523-535.

[26].Gao, J., Gen, M., Sun, L., \& Zhao, X. (2007). "A hybrid of genetic algorithm and bottleneck shifting for multiobjective flexible job shop scheduling problems". Computers \& Industrial Engineering, 53(1), 149-162.

[27].Xia, W., \& Wu, Z. (2005). "An effective hybrid optimization approach for multi-objective flexible job-shop scheduling problems". Computers \& Industrial Engineering, 48(2), 409-425.

[28].Moradi, E., Ghomi, S. F., \& Zandieh, M. (2011). "Bi-objective optimization research on integrated fixed time interval preventive maintenance and production for scheduling flexible job-shop problem". Expert systems with applications, 38(6), 7169-7178.

i. Naranje, V., \& Kumar, S. (2014). “A knowledge based system for automated design of deep drawing die for axisymmetric parts". Expert Systems with Applications, 41(4), 1419-1431.

ii. Da Silva, J. C., Matelli, J. A., \& Bazzo, E. (2014). "Development of a knowledge-based system for cogeneration plant design: Verification, validation and lessons learned”. Knowledge-Based Systems, 67, 230-243.

iii. Noorul Haq, A., Ramanan, T. R., Shashikant, K. S., \& Sridharan, R. (2010). "A hybrid neural network-genetic algorithm approach for permutation flow shop scheduling". International Journal of Production Research, 48(14), 4217-4231.

iv. Mejía, G., Montoya, C., Cardona, J., \& Castro, A. L. (2012). "Petri nets and genetic algorithms for complex manufacturing systems scheduling”. International Journal of Production Research, 50(3), 791-803.

v. Tanaka, Y., \& Yoshida, T. (1999). “An application of reinforcement learning to manufacturing scheduling problems. Paper presented at the Systems, Man, and Cybernetics”, 1999. IEEE SMC'99 Conference Proceedings. 1999 IEEE International Conference on.

vi. Azadeh, A., Negahban, A., \& Moghaddam, M. (2012). “A hybrid computer simulation-artificial neural network algorithm for optimisation of dispatching rule selection in stochastic job shop scheduling problems". International Journal of Production Research, 50(2), 551-566.

vii. Yao, X., Zhang, Y., Li, B., Zhang, Z., \& Shen, X. (2013). “Machining force control with intelligent compensation”. The International Journal of Advanced Manufacturing Technology, 69(5-8), 1701-1715. 
viii. Méndez, G., Colás, R., Leduc, L., Lopez-Juarez, I., \& Longoria, R. (2012). "Finishing mill thread speed set-up and control by interval type 1 non-singleton type 2 fuzzy logic systems". Ironmaking \& Steelmaking, 39(5), 342-354.

ix. Zuperl, U., Cus, F., \& Reibenschuh, M. (2012).” Modeling and adaptive force control of milling by using artificial techniques”. Journal of Intelligent Manufacturing, 23(5), 1805-1815.

x. Liao, W., Wang, Y., \& Pan, E. (2012). "Single-machine-based predictive maintenance model considering intelligent machinery prognostics". The International Journal of Advanced Manufacturing Technology, 63(1-4), 51-63.

xi. Yang, B.-S. (2012).” An intelligent condition-based maintenance platform for rotating machinery”. Expert Systems with Applications, 39(3), 2977-2988.

xii. Yuniarto, M., \& Labib, A. (2006). "Fuzzy adaptive preventive maintenance in a manufacturing control system: a step towards self-maintenance”. International Journal of Production Research, 44(1), 159-180.

xiii. Fouad, R. H., Samhouri, M. S., \& Qamar, A. M. (2012). “An Intelligent Preventive Maintenance Scheduling in ERP Systems: A Fuzzy Logic Approach”. International Journal of Advancements in Computing Technology, 4(23).

xiv. Samhouri, M. S. (2009). “An intelligent opportunistic maintenance (OM) system: a genetic algorithm approach”. Paper presented at the Science and Technology for Humanity (TIC-STH), 2009 IEEE Toronto International Conference.

xv. Wu, B., Tian, Z., \& Chen, M. (2013). “Condition-based Maintenance Optimization Using Neural Network-based Health Condition Prediction". Quality and Reliability Engineering International, 29(8), 1151-1163.

xvi. Jovanović, R. Ž., Sretenović, A. A., \& Živković, B. D. (2015).” Ensemble of various neural networks for prediction of heating energy consumption”. Energy and Buildings, 94, 189-199.

xvii. Chou, J.-S., \& Bui, D.-K. (2014). "Modeling heating and cooling loads by artificial intelligence for energy-efficient building design". Energy and Buildings, 82, 437-446.

xviii. Awan, S. M., Aslam, M., Khan, Z. A., \& Saeed, H. (2014). "An efficient model based on artificial bee colony optimization algorithm with Neural Networks for electric load forecasting”. Neural Computing and Applications, 25(7-8), 1967-1978. xix. Nassif, N. (2012). "Modeling and Optimization of HVAC Systems Using Artificial Intelligence Approaches”. ASHRAE Transactions, 118(2).

xx. Xu, Y., Ji, K., Lu, Y., Yu, Y., \& Liu, W. (2013). “Optimal building energy management using intelligent optimization”. Paper presented at the Automation Science and Engineering (CASE), 2013 IEEE International Conference on.

xxi. Li, N., Chen, L., \& Low, S. H. (2011). "Optimal demand response based on utility maximization in power networks". Paper presented at the Power and Energy Society General Meeting, 2011 IEEE.

xxii. Eberspächera, P., \& Verla, A. (2013). "Realizing energy reduction of machine tools through a control-integrated consumption graph-based optimization method". Procedia CIRP, 7, 640-645.

xxiii. Orio, G. D., Cândido, G., Barata, J., Bittencourt, J. L., \& Bonefeld, R. (2013). “Energy Efficiency in Machine Tools-A SelfLearning Approach". Paper presented at the Systems, Man, and Cybernetics (SMC), 2013 IEEE International Conference on. xxiv. Mouzon, G., Yildirim, M. B., \& Twomey, J. (2007). "Operational methods for minimization of energy consumption of manufacturing equipment”. International Journal of Production Research, 45(18-19), 4247-4271.

xxv. Moon, J. Y., \& Park, J. (2011). "Modeling and optimization of unrelated parallel machine scheduling problem with timedependent and machine-dependent electricity cost”. International Journal of Advanced Manufacturing Technology, 68(1-4), 523-535. xxvi. Gao, J., Gen, M., Sun, L., \& Zhao, X. (2007). “A hybrid of genetic algorithm and bottleneck shifting for multiobjective flexible job shop scheduling problems". Computers \& Industrial Engineering, 53(1), 149-162.

xxvii. Xia, W., \& Wu, Z. (2005). “An effective hybrid optimization approach for multi-objective flexible job-shop scheduling problems". Computers \& Industrial Engineering, 48(2), 409-425.

xxviii. Moradi, E., Ghomi, S. F., \& Zandieh, M. (2011). "Bi-objective optimization research on integrated fixed time interval preventive maintenance and production for scheduling flexible job-shop problem". Expert systems with applications, 38(6), 71697178. 